\title{
Automated glycan assembly of arabinomannan oligosaccharides from Mycobacterium tuberculosis
}

\author{
Alonso Pardo-Vargas ${ }^{1,2}$, Priya Bharate ${ }^{1}$, Martina Delbianco ${ }^{1}$ and Peter H. Seeberger ${ }^{* 1,2}$
}

\author{
Full Research Paper \\ Address: \\ ${ }^{1}$ Department of Biomolecular Systems, Max-Planck-Institute of \\ Colloids and Interfaces, Am Mühlenberg 1, 14476 Potsdam, Germany \\ and ${ }^{2}$ Institute of Chemistry and Biochemistry, Freie Universität Berlin, \\ Arnimallee 22, 14195 Berlin, Germany \\ Email: \\ Peter H. Seeberger* - peter.seeberger@mpikg.mpg.de \\ * Corresponding author \\ Keywords: \\ arabinomannan; automated glycan assembly; capping
}

Beilstein J. Org. Chem. 2019, 15, 2936-2940. doi:10.3762/bjoc. 15.288

Received: 29 October 2019

Accepted: 28 November 2019

Published: 06 December 2019

Associate Editor: I. Baxendale

(C) 2019 Pardo-Vargas et al.; licensee Beilstein-Institut. License and terms: see end of document.

\begin{abstract}
Arabinomannan (AM) polysaccharides are clinical biomarkers for Mycobacterium tuberculosis (MTB) infections due to their roles in the interaction with host cells and interference with macrophage activation. Collections of defined AM oligosaccharides can help to improve the understanding of these polysaccharides and the development of novel therapeutical and diagnostic agents. Automated glycan assembly (AGA) was employed to prepare the core structure of AM from MTB, containing $\alpha$ - $(1,6)-$ Man, $\alpha$ - $(1,5)$-Ara, and $\alpha$-(1,2)-Man linkages. The introduction of a capping step after each glycosylation and further optimized reaction conditions allowed for the synthesis of a series of oligosaccharides, ranging from hexa- to branched dodecasaccharides.
\end{abstract}

\section{Introduction}

Bacterial infections caused by MTB killed 1.7 million people in 2017. Additionally, more than 10 million new tuberculosis (TB) cases were reported, with multidrug-resistant TB accounting for almost $10 \%$ of the registered cases [1]. The development of novel therapeutic agents and more efficient strategies to detect MTB infections at an early stage is essential, as an early diagnosis would help to prevent most deaths from tuberculosis [1]. AMs, one of the main components of the mycobacterial cell wall [2], are composed of $\alpha-(1,5)-, \alpha-(1,3)$ - and $\beta$-(1,2)-arabinoses as well as $\alpha-(1,6)$ - and $\alpha$-(1,2)-mannosides [3-5]. AMs are potential clinical biomarkers for infection [6-10] due to their roles in the interaction with host cells, interference with macrophage activation, and immunosuppression of $\mathrm{T}$ cell responses $[11,12]$. Diagnosis of tuberculosis in patients with HIV coinfec- tions is possible by immunodetection of AMs and their lipidated lipoarabinomannan (LAM) analogs in urine samples using the Alere lateral flow urine (LF)-LAM assay [13]. However, the low sensitivity of the Alere assay limits its scope. Glycan array screening of more than 100 monoclonal antibodies against more than 60 synthetic glycans related to the mycobacterial cell wall helped to identify an antibody targeting the 5-methylthio-D-xylofuranose AM [7,14]. The Fujifilm SILVAMP TB LAM immunoassay chip provided a threefold higher sensitivity than Alere LF-LAM. Still, current technologies lack sensitivity and are limited to patients coinfected with HIV [7,10,15]. Identification of novel anti-TB agents that specifically target AMs with high sensitivity are required. Pure AM oligosaccharides may help to identify new lead com- 
pounds for the development of diagnostics. Since the isolation of pure oligosaccharides from MTB strains in sufficient quantities is challenging, the chemical synthesis of AM is an attractive alternative. AM polysaccharides as large as 92-mers as well as many shorter AM oligomers have been prepared by solutionphase synthesis [16-20]. These multi-step syntheses are challenging and time-consuming. AGA reduces time and effort to access complex glycans [21], including linear and branched oligoarabinofuranosides $\alpha$-(1,5)- and $\alpha$-(1,3)- [22] as well as arabinomannose $[23,24]$

Herein, we describe the AGA of oligosaccharides 4-9 that resemble portions of the MTB AM core structure (Scheme 1). Just three building blocks, namely $\mathbf{1}-\mathbf{3}$, were required to access all six oligosaccharides, ranging from hexa- to dodecasaccharides.

\section{Results and Discussion}

The automated syntheses of oligomannosides 4-6 and oligoarabinomannosides 7-9 were performed on a self-built automated synthesizer using a Merrifield resin functionalized with a photocleavable linker as solid support [25]. A typical AGA cycle consisted of three modules. The acidic wash module prepared the resin for glycosylation by quenching any remaining base from a previous cycle. In the glycosylation module, the thioglycoside donor was coupled to the resin upon activation with NIS and $\mathrm{TfOH}$ (from -40 to $-20{ }^{\circ} \mathrm{C}$ ). Finally, the deprotection module removed the temporary protecting group, such as fluorenylmethyloxycarbonyl (Fmoc) or levulinoyl (Lev), to reveal a free hydroxy group that allowed for further chain elongation in the next cycle. Fmoc and Lev were used as orthogonal temporary protecting groups, whereby Fmoc was cleaved by piperidine (20 vol \% in DMF), while Lev was removed using

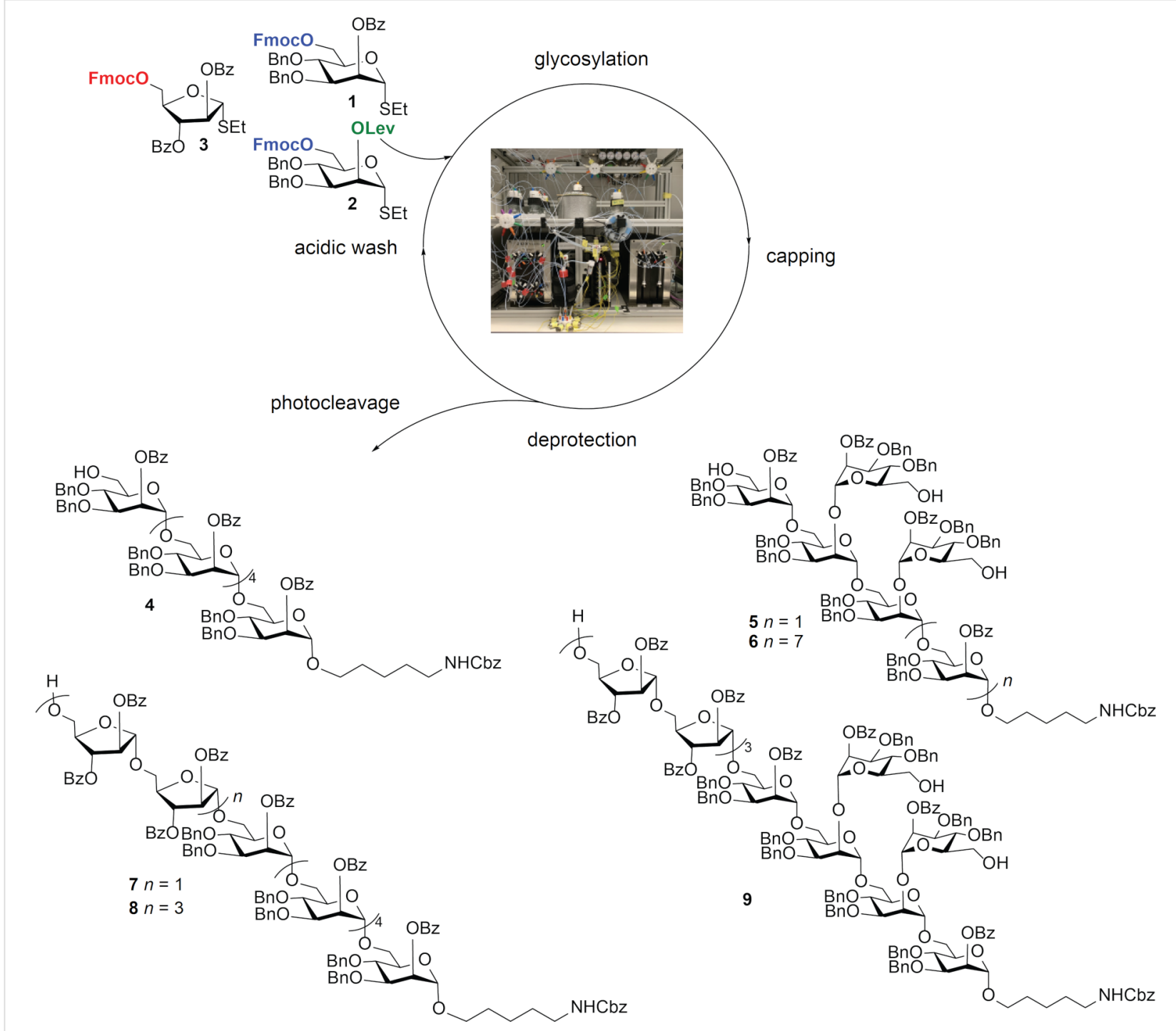

Scheme 1: Schematic representation of AGA for oligomannosides and oligoarabinomannosides using building blocks 1-3. 
hydrazine acetate. Iterative cycles continued until the desired structure was obtained. The oligosaccharide products were cleaved from the solid support using a flow UV photoreactor, followed by a two-step purification and global deprotection [25].

Linear $\alpha$-(1,6)-hexamannoside 4 was synthesized using six coupling cycles and 6.5 equiv of mannose building block (BB) 1 . No deletion sequences were observed and the crude product was purified using normal-phase HPLC to obtain hexamannoside 4 in $55 \%$ yield, based on resin loading. The doubly branched hexamannoside 5 was assembled using BB 1 for $\alpha$ - $(1,6)$ linkages and BB 2 for $\alpha-(1,6) / \alpha-(1,2)$ branching points. First, the linear $\alpha$-(1,6)-trimannose was assembled, followed by deprotection of both Lev and Fmoc to reveal three hydroxy groups. Three sequential glycosylation cycles using 6.5 equiv of BB 1 afforded compound 5 in 37\% yield. Chromatographic analysis revealed compound $\mathbf{5}$ as the major product, along with pentamer and tetramer side products from incomplete glycosylation. To improve the glycosylation efficiency, a new glycosylation module employing higher incubation and reaction temperatures (from $-20{ }^{\circ} \mathrm{C}$ to $0{ }^{\circ} \mathrm{C}$ ) was introduced (procedure B). Capping after each glycosylation prevented the formation of undesired side products [26] and improved the isolated yield of 5 to $53 \%$, with no detectable deletion sequences (Table 1).

The inclusion of a capping step in the AGA synthesis cycle (procedure B) was further illustrated in the synthesis of oligosaccharides 6-9. AGA of the branched 12-mer mannoside 6 showed a dramatic improvement, with yields rising from $6 \%$
Table 1: AGA of arabinomannosides 4-9. Procedure A modules: i) acidic wash, ii) glycosylation (from $-40{ }^{\circ} \mathrm{C}$ to $-20^{\circ} \mathrm{C}$ ), and iii) Fmoc/ Lev deprotection. Procedure $\mathrm{B}$ modules: i) acidic wash, ii) glycosylation (from $-20^{\circ} \mathrm{C}$ to $0^{\circ} \mathrm{C}$ ), iii) capping, and iv) Fmoc/Lev deprotection.

\begin{tabular}{ccc} 
compound & $\begin{array}{c}\text { procedure A } \\
\text { yields (\%) }\end{array}$ & $\begin{array}{c}\text { procedure B } \\
\text { yields (\%) }\end{array}$ \\
\hline 4 & 55 & - \\
5 & 37 & 53 \\
6 & 6 & 48 \\
7 & 9 & 56 \\
8 & 7 & 61 \\
9 & 3 & 26 \\
\end{tabular}

(procedure A) to $48 \%$ (procedure B). Syntheses of linear octamer-arabinomannoside 7 and linear 12-mer 8 were addressed using building block $\mathbf{1}$ and arabinose BB $\mathbf{3}$ for the $\alpha$-(1,5)-Ara linkage. Procedure A efficiently provided the linear mannose backbone, but resulted only in partial glycosylation of arabinose BB 3, thus giving the hexamannoside as main product as well as multiple side products missing one or more arabinoses. The desired products $\mathbf{7}$ and $\mathbf{8}$ were isolated in only 9 and $7 \%$ yield, respectively. In contrast, most deletion sequences were absent and $\mathbf{7}$ and $\mathbf{8}$ were isolated in 56 and $61 \%$ yield, respectively, when procedure B was employed.

The advantage of the new procedure became more apparent for AGA of dodecamer 9, which required all three BBs. While procedure A yielded just 3\% dodecamer 9 (Figure 1a), procedure B gave 9 as the major product (26\%, Figure $1 b)$.
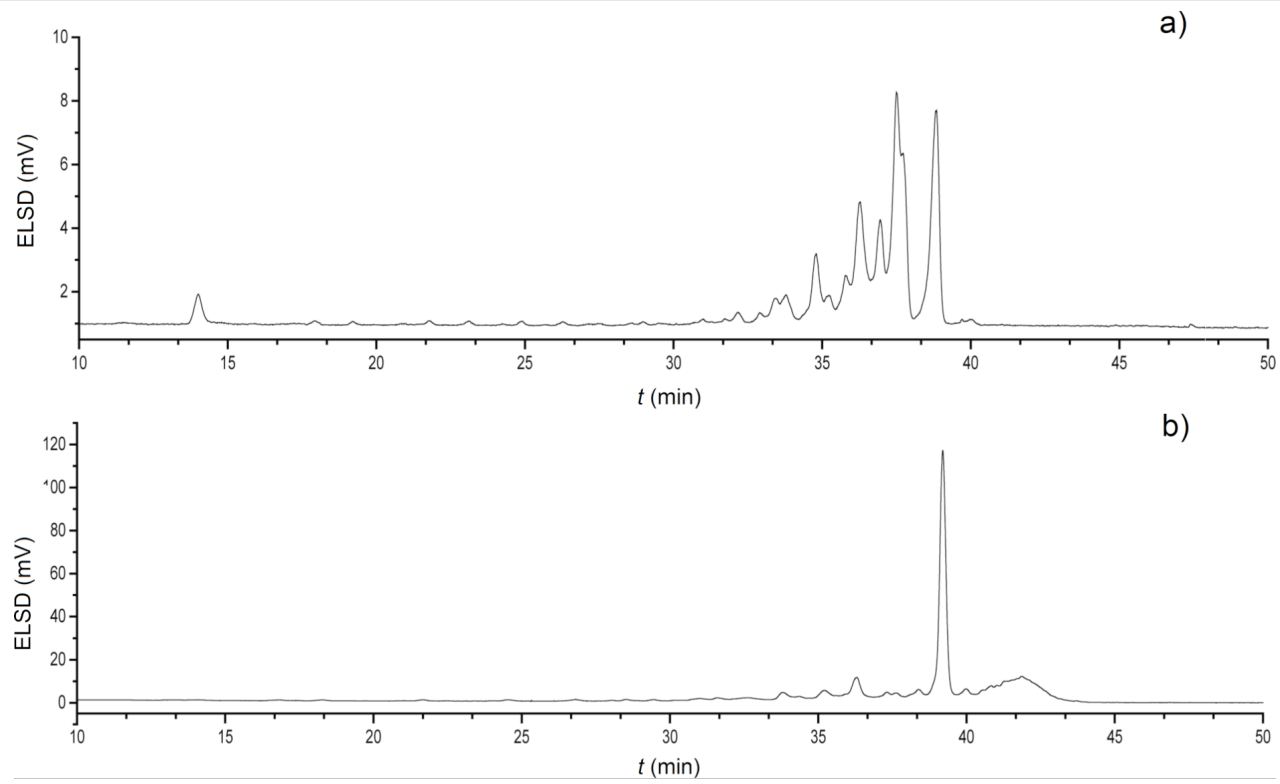

Figure 1: HPLC chromatograms of crude dodecamer 9. a) Results obtained with AGA procedure A. b) Results obtained with AGA procedure B. For detailed procedures, see Tables S10 and S11 in Supporting Information File 1. 


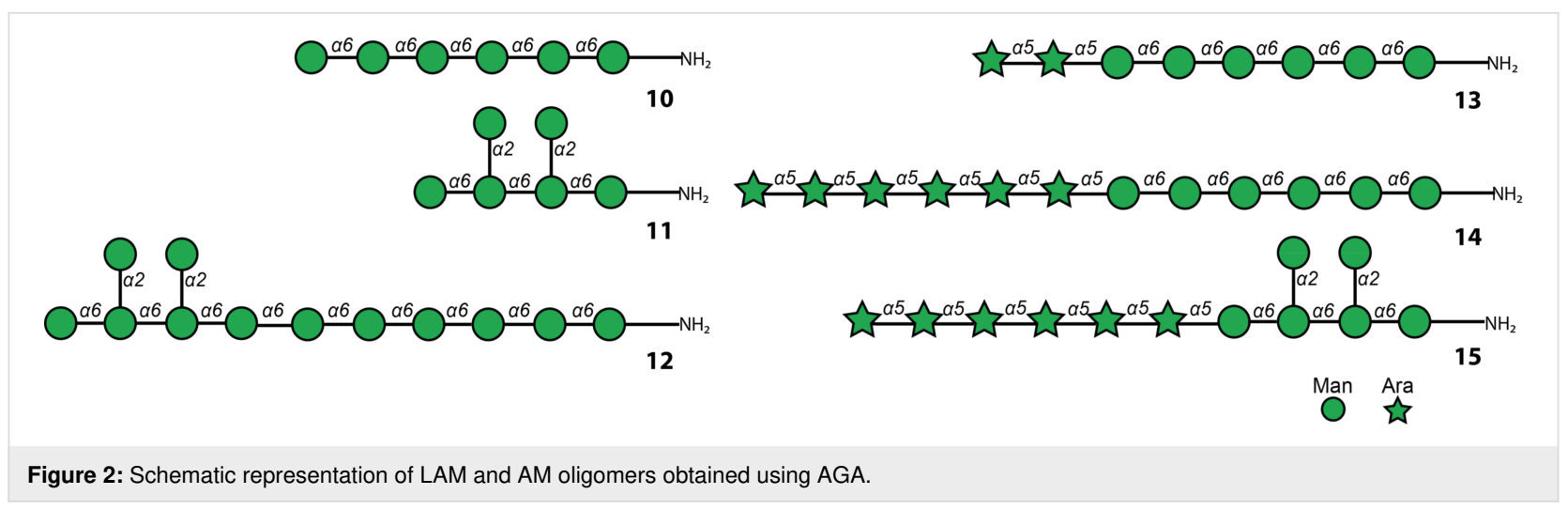

The global deprotection of oligosaccharides 4-9 was achieved by removal of the benzoate ester protecting groups under Zemplén methanolysis, followed by $\mathrm{Pd} / \mathrm{C}$-catalyzed hydrogenolysis of the carboxybenzyl group and the benzyl ethers. Mannosides 4-6 were deprotected and purified using reversedphase HPLC to obtain fully deprotected mannosides 10-12 (Figure 2). For the arabinomannosides 7-9, the acid-labile arabinose chain was cleaved during hydrogenation, giving a complex mixture of deletion sequences lacking one to six arabinose moieties. To overcome this challenge, hydrogenolysis with $\mathrm{Pd}(\mathrm{OH})_{2}$ was performed to access the fully deprotected arabinomannosides 13-15 (Figure 2).

\section{Conclusion}

A collection of AM oligosaccharides containing $\alpha-(1,6)-$ Man, $\alpha$-(1,5)-Ara, and $\alpha$-(1,2)-Man was synthesized by AGA using three monosaccharide building blocks. The linear oligomannosides were readily assembled and isolated in short time and high yield under standard conditions. The introduction of a capping step after each glycosylation and optimized reaction conditions allowed for the synthesis of larger oligosaccharides. The resulting oligosaccharides will be used to study the substructure-specific antibody recognition of arabinomannans.

\section{Supporting Information}

\section{Supporting Information File 1}

NMR spectra of AM and detailed information on AGA.

[https://www.beilstein-journals.org/bjoc/content/

supplementary/1860-5397-15-288-S1.pdf]

\section{Acknowledgements}

We gratefully acknowledge financial support from the Max Planck Society, the EU ITN Marie-Curie program (IMMUNOSHAPE - Grant no. 642870), the Minerva Fast Track Program, and the MPG-FhG Cooperation Project Glyco3Dysplay. We also thank Dr. Kim Le Mai Hoang for the proofreading of the manuscript. This work used Dr. Bharate's thesis "Automated Glycan Assembly of Oligomannose Glycans for Sensing Applications" as a source.

\section{ORCID ${ }^{\circledR}$ iDs}

Martina Delbianco - https://orcid.org/0000-0002-4580-9597 Peter H. Seeberger - https://orcid.org/0000-0003-3394-8466

\section{References}

1. Global Tuberculosis Report 2018. World Health Organization: Geneva, 2018; https://apps.who.int/iris/handle/10665/274453 (accessed Oct 29, 2019).

2. Angala, S. k.; Palčeková, Z.; Belardinelli, J. M.; Jackson, M. Nat. Chem. Biol. 2018, 14, 193-198. doi:10.1038/nchembio.2571

3. Besra, G. S.; Khoo, K.-H.; McNeil, M. R.; Dell, A.; Morris, H. R.; Brennan, P. J. Biochemistry 1995, 34, 4257-4266. doi:10.1021/bi00013a015

4. Shi, L.; Berg, S.; Lee, A.; Spencer, J. S.; Zhang, J.; Vissa, V.; McNeil, M. R.; Khoo, K.-H.; Chatterjee, D. J. Biol. Chem. 2006, 281, 19512-19526. doi:10.1074/jbc.m513846200

5. Briken, V.; Porcelli, S. A.; Besra, G. S.; Kremer, L. Mol. Microbiol. 2004, 53, 391-403. doi:10.1111/j.1365-2958.2004.04183.x

6. Owens, N. A.; Young, C. C.; Laurentius, L. B.; De, P.; Chatterjee, D.; Porter, M. D. Anal. Chim. Acta 2019, 1046, 140-147. doi:10.1016/j.aca.2018.09.037

7. Sigal, G. B.; Pinter, A.; Lowary, T. L.; Kawasaki, M.; Li, A.; Mathew, A.; Tsionsky, M.; Zheng, R. B.; Plisova, T.; Shen, K.; Katsuragi, K.; Choudhary, A.; Honnen, W. J.; Nahid, P.; Denkinger, C. M.; Broger, T. J. Clin. Microbiol. 2018, 56, No. e01338-18. doi:10.1128/jcm.01338-18

8. Chang, Y.; Meng, X.; Li, Y.; Liang, J.; Li, T.; Meng, D.; Zhu, T.; Yu, P. MedChemComm 2019, 10, 543-553. doi:10.1039/c8md00546j

9. Amin, A. G.; De, P.; Spencer, J. S.; Brennan, P. J.; Daum, J.; Andre, B. G.; Joe, M.; Bai, Y.; Laurentius, L.; Porter, M. D.; Honnen, W. J.; Choudhary, A.; Lowary, T. L.; Pinter, A.; Chatterjee, D. Tuberculosis 2018, 111, 178-187. doi:10.1016/j.tube.2018.06.004

10. Choudhary, A.; Patel, D.; Honnen, W.; Lai, Z.; Prattipati, R. S.; Zheng, R. B.; Hsueh, Y.-C.; Gennaro, M. L.; Lardizabal, A.; Restrepo, B. I.; Garcia-Viveros, M.; Joe, M.; Bai, Y.; Shen, K.; Sahloul, K.; Spencer, J. S.; Chatterjee, D.; Broger, T.; Lowary, T. L.; Pinter, A. J. Immunol. 2018, 200, 3053-3066. doi:10.4049/jimmunol.1701673

11. Counoupas, C.; Pinto, R.; Nagalingam, G.; Britton, W. J.; Triccas, J. A. Vaccine 2018, 36, 2619-2629. doi:10.1016/j.vaccine.2018.03.066 
12. Lindenstrøm, T.; Agger, E. M.; Korsholm, K. S.; Darrah, P. A.;

Aagaard, C.; Seder, R. A.; Rosenkrands, I.; Andersen, P. J. Immunol. 2009, 182, 8047-8055. doi:10.4049/jimmunol.0801592

13. Lawn, S. D.; Gupta-Wright, A. Trans. R. Soc. Trop. Med. Hyg. 2016, 110, 180-185. doi:10.1093/trstmh/trw008

14. Zheng, R. B.; Jégouzo, S. A. F.; Joe, M.; Bai, Y.; Tran, H.-A.; Shen, K.; Saupe, J.; Xia, L.; Ahmed, M. F.; Liu, Y.-H.; Patil, P. S.; Tripathi, A.; Hung, S.-C.; Taylor, M. E.; Lowary, T. L.; Drickamer, K. ACS Chem. Biol. 2017, 12, 2990-3002. doi:10.1021/acschembio.7b00797

15. Broger, T.; Sossen, B.; du Toit, E.; Kerkhoff, A. D.; Schutz, C.; Ivanova Reipold, E.; Ward, A.; Barr, D. A.; Macé, A.; Trollip, A.; Burton, R.; Ongarello, S.; Pinter, A.; Lowary, T. L.; Boehme, C.; Nicol, M. P.; Meintjes, G.; Denkinger, C. M. Lancet Infect. Dis. 2019, 19, 852-861. doi:10.1016/s1473-3099(19)30001-5

16. Maiti, K.; Syal, K.; Chatterji, D.; Jayaraman, N. ChemBioChem 2017, 18, 1959-1970. doi:10.1002/cbic.201700247

17. Sahloul, K.; Lowary, T. L. J. Org. Chem. 2015, 80, 11417-11434. doi:10.1021/acs.joc.5b02083

18. Hölemann, A.; Stocker, B. L.; Seeberger, P. H. J. Org. Chem. 2006, 71 8071-8088. doi:10.1021/jo061233x

19. Wu, Y.; Xiong, D.-C.; Chen, S.-C.; Wang, Y.-S.; Ye, X.-S. Nat. Commun. 2017, 8, No. 14851. doi:10.1038/ncomms 14851

20. Islam, M.; Shinde, G. P.; Hotha, S. Chem. Sci. 2017, 8, 2033-2038. doi:10.1039/c6sc04866h

21. Guberman, M.; Seeberger, P. H. J. Am. Chem. Soc. 2019, 141, 5581-5592. doi:10.1021/jacs.9b00638

22. Kandasamy, J.; Hurevich, M.; Seeberger, P. H. Chem. Commun. 2013, 49, 4453-4455. doi:10.1039/c3cc00042g

23. Hahm, H. S.; Schlegel, M. K.; Hurevich, M.; Eller, S.; Schuhmacher, F.; Hofmann, J.; Pagel, K.; Seeberger, P. H. Proc. Natl. Acad. Sci. U. S. A. 2017, 114, E3385-E3389. doi:10.1073/pnas.1700141114

24. Pardo-Vargas, A.; Delbianco, M.; Seeberger, P. H. Curr. Opin. Chem. Biol. 2018, 46, 48-55. doi:10.1016/j.cbpa.2018.04.007

25. Eller, S.; Collot, M.; Yin, J.; Hahm, H. S.; Seeberger, P. H. Angew. Chem., Int. Ed. 2013, 52, 5858-5861. doi:10.1002/anie.201210132

26. Yu, Y.; Kononov, A.; Delbianco, M.; Seeberger, P. H. Chem. - Eur. J. 2018, 24, 6075-6078. doi:10.1002/chem.201801023

\section{License and Terms}

This is an Open Access article under the terms of the Creative Commons Attribution License (http://creativecommons.org/licenses/by/4.0). Please note that the reuse, redistribution and reproduction in particular requires that the authors and source are credited.

The license is subject to the Beilstein Journal of Organic Chemistry terms and conditions: (https://www.beilstein-journals.org/bjoc)

The definitive version of this article is the electronic one which can be found at: doi:10.3762/bjoc. 15.288 